\title{
Analysis of the current situation and enlightenment of Harbin popular
}

\section{culture consumption}

\author{
FangZhou Cheng ${ }^{1, \text { a }}$, SongMei Yuan ${ }^{2, b}$ \\ ${ }^{1}$ Harbin Institute of Technology, 92 West Dazhi Street, Harbin 150001, China \\ ${ }^{2}$ Harbin Institute of Technology, 92 West Dazhi Street, Harbin 150001, China ${ }^{a}$ \\ airong1sheng@qq.com , byuansm518@sina.com
}

Keywords: Harbin City; Popular culture consumption; Culture industry; Resident power of consumption; Public cultural service

\begin{abstract}
With the rapid development of our economy, and resident income level rise ceaselessly, cultural consumption has become an absolutely necessary important part of consumption structure of residents. Cultural consumption as the final links in the cultural industry chain and it also an important force to promote the upgrading of consumption structure. It has a great significance for stimulate cultural production, promoting economic growth, enhancing the overall quality of our nationals and setting up harmonious society. To satisfy the requirements of the national development and construction as well as people's increasing demand for cultural consumption, enhancing the social spirit in the perspective of social culture and making a good job of city cultural construction has been one of the important matters in development throughout china.
\end{abstract}

\section{Introduction}

Since the reform and opening policy, China's city construction has been developed by leaps and bounds; the Public cultural service system has been more perfect improved and the development of cultural industry has made great achievements. However, the providing of universal, public welfare culture cannot meet the demand of the public spiritual and cultural products, and it also restricted the cultural development of the city. The study of City mass cultural consumption is not only propitious to promoting of cultural industries development especially the healthy development of the field of cultural consumption, but also it has the important real significance and far-reaching historical significance for promoting the city economic competition and promoting the city's cultural construction.

\section{The connotation and basic characteristics of the residents' cultural consumption}

Popular culture consumption, which means people in order to meet the spiritual and cultural needs of their own, consuming in the spiritual and cultural products or services, and the consumption is mainly focused on the aspect of education, culture, sports, tourism and leisure entertainment. At the same time this kind of consumption process is the process of innovation in spiritual civilization wealth digestion, savings, inheritance and innovation. [1] With the pace of reform and opening up the magnificent, our country's comprehensive strength is steadily increasing. In the late 90's, the culture industry has appeared as a new industry form, and became an important new economic growth point. 
At present, the vigorous development of cultural industries is promoting the transformation of economic growth mode.

\section{Our country's mass culture consumption has the following basic characteristics:}

The characteristic of cultural consumption has a popular way. [2] With the rapid development of our economy, and resident income level rise ceaselessly. The scope of cultural consumption is gradually increasing in the two aspects of both the width and breadth of regional strata.

The cultural consumption has the characteristics of high tech.[3] In recent years, china's electricity business and Internet business are rapid increasing. And durable household culture product are unceasingly upgrading. The proportion of digital technology application that has been used in the consumer culture and cultural consumption is ceaseless increasing.

The characteristic of cultural consumption has a young style. The young group has the more energy and financial resources and a more spiritual consumption demand, its content of consumption are mainly focused on the popular entertainment culture.

Cultural consumption level is synchronized with residents' education level. With the increasing of city residents' knowledge level and self - cultivation improvement in our country, the proportion of consumption that resident has putted into the cultural consumption are increasing.

\section{Cultural consumption survey in Harbin}

The author had made the questionnaire and hand them out in Harbin's streets, and it had got the 130 effective samples from the interviewees. Comprehensive analysis of survey data and analysis related research results; it got the cultural consumption status in Harbin.

The Consumption culture identity is more and more strong. [4]Harbin resident per capita income level has been supported residents' to joining all kinds of cultural consumption, in the future, with the increasing of Harbin dweller standard of living and optimization way of life.

People keep an optimistic attitude towards Harbin construction of city culture. Harbin residents keep a full of expectation toward to the construction of city culture. They hope Harbin will put great efforts to making all kinds of municipal public cultural activities, and regular free open culture and arts venues.

Cultural consumption has a great sum of the shallow level of consumption, and lacking of deep level of consumption. The mainly obstacles focusing on these areas: people lack time to consume, the price of cultural consumption is too high, and the environment lack of cultural consumption atmosphere.

The hierarchy of needs in cultural consumption is gradually developing to deep level. During the progress of resident cultural consumption, and they pay more attention to the content of the product and its spiritual enjoyment. The residents' consumer demand has increased to the deep level of demand for spiritual and cultural consumption.

Cultural consumption demand of communicative function, positive energy is increasing. During the progress of cultural consumption, residents are more prefer cultural consumption projects that are more positive and express "positive energy" and bring aesthetic experience, at the same time, it is also worth to be aftertaste and taking it as a social communication capital.

Consumer platform is more technology. In the culture of consumption, residents' cultural consumption activities are transfer from the traditional media to Network media and online culture. 
Cultural consumption payment has been transferred to the E-bank payment.

\section{Analysis of influencing factors and existing problems in Harbin cultural consumption}

Historical and cultural places of consumption lacks guide of repeated consumption behavior of residents. Harbin, as a tourist city, its historical cultural relics has got the wonderful protection and development. However, Harbin history of cultural consumption is mainly "single" consumption. Its article of consumption cannot attract the local city residents review cultural consumption.

Cultural consumption has been existed the trouble of low levels of homogeneity. The lack of related knowledge and the law of the development of cultural industry are common problems in the trade. There are misinterpreting the focus of competition, or even inclination of hardware and estate.

Many enterprise cultures are not market-oriented, instead they are policy oriented. Private enterprises as an important force to promote the development of cultural industry, it has many advantages, however, the error management will lead to part of the private enterprises cannot find its market positioning and development direction, during their course of business.

Harbin has a shortage of cultural service industry talent people. [5] With the further deepen reform in Harbin cultural Services, and Harbin resident cultural consumption has changed from the type consumption by material to the service consumption, and Harbin cultural industry labor costs is gradually increasing. "Hire difficult question" is still one of the main bottlenecks for development.

\section{The inspiration of Harbin popular culture consumption}

Analyze of Harbin culture consumption. Harbin is the provincial capital of Heilongjiang Province, which is the most northern of the People's Republic of China. Harbin is the political, economic, cultural center in northeast of china. [6] Harbin has always take "the spirit of Harbin", as "open and inclusive, ahead of fashion and vitality, integrity, harmony" [7]as the provincial capital of Heilongjiang Province, which is the most northern of the People's Republic of China, Harbin has its special cultural features of the Northeast. Because of its Climate characteristics, Harbin has shaped full-bodied "ice and snow" culture." ice city" Harbin is praised as "the Orient Moscow".

History cultural consumption: Harbin is the national famous historical and cultural city, the city owns cultural heritages such as: century - old history building- St. Sophia's church, and the center street with Russia amorous feelings, "a catastrophic flood in the year of 1957" memorial tower against flood, a complete regulation of Confucius' Temple that was the final completed in the country, Jile Temple of Harbin, Sun Island Scenic Area, The former residence of Xiao Hong, The Soviet Red Army Martyrs Monument

Regional characteristics cultural consumption: "Jin Dynasty Culture" which is based on the NV Zhen nationality traditional culture and "Beijing Flag Culture" which was emerged in middle term of Qing dynasty, all of these had exhibited Harbin's northern nationalities long history.

Seasonal consumption culture: since early of 1980s, related project of Harbin "ice and snow culture" has got achievement. [8] It including cultural consumption project of "ice and snow festival", international ice engraving and snow mound racing, Ice lantern garden party, snow and ice world, Yabuli Ski Resort, Harbin Polar Museum, Ice Wedding in Harbin youth palace.

Traditional cooperation type of cultural consumption: Harbin has many international co-operation Historical and cultural traditions project. It including: "The summer of Harbin" concert, which is known as one of "great three concerts" in china, it has 24 sessions of the history, and it 
changed the name into "Chinese Russia Expo", "Ha Qiahui" and all kinds of cultural and Art Industry Expo.

\section{Countermeasures and suggestions in Harbin construction of cultural consumption}

Developing tourism cultural industry with culture feelings. In adherence to the "Authenticity", based on the cultural industries in Harbin traditional cultural resources as an important development in tourism development target, combined with the development of both can have the ability to update the activity as "cultural tourism", will Harbin heritage and achieve more scientific and rational development, the promotion and protection of traditional cultural heritage resources.

Building Innovative cultural services on the Internet. Service innovation is to increase the tangible or intangible "product" of the value-added economic activities by means of non-material fabrication performed. Now active in the Internet industry, along with the rapid development of information technology, making the Internet technology products and product features are available to obtain high-quality security, the establishment and development of the Internet is the best time of cultural services.

Making Harbin museum's mobile platform, Harbin has more than 20 museums and they also undertake various international, national and cultural activities. Through the establish of mobile platform, it can pull together of all the information in museum, and making unified information release platform and personalized service customization, and set up Harbin museum products brand.

Construction city culture information query platform. Cultural activities are active constituent units of urban culture; it is an important part of urban residents in cultural life. It can set up digitized cultural newspaper project activities, and making online cultural advertising exhibition, using Interactive media to interaction with residents. Using of the Internet massive audience base, fast and convenient internet cultural services and other advantages can be spread steadily build up a sound system.

Establish with the university culture learning city image. Harbin has many institutions of higher education, including Harbin Institute of Technology, Heilongjiang University, Northeast Agricultural University, and Northeast Forestry University, Each of these institutions has a unique cultural and spiritual wealth has a solid deep cultural roots. Campus culture has a guide, inspire, edify and cohesion of moral function, and taking "college culture" into the city's cultural image, will enhance the overall image of urban culture Harbin.

Developing tourism projects in the university culture. With the "cultural tourism" development, Harbin institution development and establish the image of not only conducive to the development of culture Harbin, it will be more conducive to learning their own propaganda and campus culture construction of campus culture.

\section{Summary}

Vigorously promote the consumption of popular culture is the inevitable choice to accelerate the development of cultural industry; it is also an inevitable choice for the construction of the city's culture. For the city to promote the strategic adjustment of economic structure, promote the socialist core value system, improving residents' consumption structure, improve the cultural quality of residents, a sense of belonging and so has an irreplaceable role in the cultural industry. Consumption of urban popular culture research, cultural construction of urban residents in cultural consumption advice is to promote the development of effective measure of cultural industries. 


\section{References}

[1]HuiLin Hu /KangHua Li. Cultural Economics Chapter IV[M]. Shanghai Literature and Ar t Publishing House 2003-2-1

[2]NianKuan Hong. The study of Mass Cultural Consumption and Its Characteristics[J] Journ al of Xichang College 2005, 17(2)

[3] KaiLin Du. Development of socialism with Chinese characteristics and cultural industries Nanjing Normal University[R]. 2011

[4Investigation of Harbin popular culture[N]. Harbin new evening news 2013-10-31

[5] 187 service enterprises sample survey in Harbin[Z].National Bureau of Statistics 2013

[6]Review of Harbin city. China[Z]. 2013-09-24

[7]Decided by Harbin municipal Party Committee Standing Committee[Z]. 2005-8-8

[8] Harbin Cultural Bureau of Harbin cultural overview[Z].

\# This article is stage of the research resultsin the year 2012 in Heilongjiang Province Arts and Sciences and planning issues (ID: 12D009) 